\title{
Use of Particle Image Velocimetry (PIV) technique to measure strains in geogrids
}

\author{
Chaminda Gallage ${ }^{1, *}$ and Chamara Jayalath ${ }^{1}$ \\ ${ }^{1}$ Queensland University of Technology, School of Civil Engineering and Built Environment, QLD, Australia
}

\begin{abstract}
Geosynthetics are widely used in Geotechnical Engineering to reinforce soil/gravel in pavements, retaining wall backfills, and embankments. It is important to measure strains in geogrids in the determination of their strength parameters such as tensile strength and secant stiffness, and in evaluating their performances in geogrid-reinforced structures. Strain gauges are commonly used in measuring strains in geogrids. However, it is important to verify the strains measured by strain gauges as these strains are affected by the data logging device, gauge factors, quality of bonding between grain gauge and geogrid, and temperature. Therefore, this study was conducted to verify the performance of strain gauges attached to Geogrids and also to investigate the possibility of using PIV technique and GeoPIV-RG software to measure the local strains developed in a geogrid specimen under tensile testing in the laboratory. In the experimental program of this study, six composite geogrid specimens were tested for tensile strength (widewidth tensile tests) while measuring/calculating its tensile strain by using strain gauges attached to the specimens, Geo-PIV-RG analysis and crosshead movements of Instron apparatus. Good agreement between the strains obtained from strain gauges and geoPIV-RG analysis was observed for all the tests conducted. These results suggest that the PIV technique along with geoPIV-RG program can effectively be used to measure the local strain of geogrids in the laboratory tests. It was also able to verify that properly installed strain gauges are able to measure strain in the geogrids which are used in the field applications.
\end{abstract}

\section{Introduction}

Geosynthetic products are widely used in Geotechnical Engineering to reinforce soil/gravel in pavements, retaining wall backfills, and embankments. The main functions of geosynthetic materials are separation, filtration, reinforcement, stiffening, drainage, hydraulic or gas barrier and protection [1]. It has been recognised that inclusion of composite geogrids which are the geogrids combined with a nonwoven geotextile component, into the pavement structure helps to maximise the benefits of geosynthetic-reinforcement in flexible pavements. In this context, evaluating the strain behaviour of composite geogrid under tensile load is important in the development and validation of numerical models that can be used to predict the behaviour of geogrid-reinforced flexible pavements [2]. Similarly, it is important to measure strains in geogrids in the determination of their strength parameters such as tensile strength and secant stiffness, and in evaluating their performances in geogrid-reinforced structures. It is well known that wide-width tensile test [3] is commonly used to characterise the stress-strain properties of these materials.

It is essential to continuously measure the strain development of geosynthetics during the tensile test for a better understanding of the tensile behaviour of material.
In general, the average strain developed within the test specimen is computed considering the relative displacement between the two grips. However, this strain measurement method is incapable of measuring the local strains developed within the sample due to the presence of seam, production defects, punctured zones or tear of the geosynthetic product which can significantly affect its behaviour under tensile load [4-5]. Similarly, the computed strains are influenced by the slippage of the test specimens in the clamps. Therefore, it is recommended to measure strains over a central portion of the test specimen instead of using the crosshead displacement [6].

Strain gauges are widely used in measuring local strains of test specimens; however, the measured strains are known to be slightly different from the actual strains as these sensors stiffen the geosynthetic material [2]. Further, measured strains are affected by the data logging device, gauge factors, quality of bonding between grain gauge and geogrid, and temperature. In addition, careful attention on surface preparation and gluing is required when strain gauges are attached to test specimens. Apart from that, strain gauges easily detach from the specimen surface at large strains well before the rupture of the test specimen [6]. Further, it is an expensive option when more strain gauges are needed. In addition, a difference between the strain measured by the foil strain gauge and the actual local strain at the same

\footnotetext{
* Corresponding author: chaminda.gallage@qut.edu.au
} 
location of the test specimen can exist due to above mentioned drawbacks; hence, the calibration is necessary to verify the performance of strain gauges. In order to overcome these shortcomings of strain gauges, imagebased approach such as Particle Image Velocimetry (PIV) can be used to measure the local strain of geosynthetic specimens during the tensile testing, and also to verify the performance of strain gauges.

The PIV technique along with GeoPIV-RG software has been successfully used to analyse the images from a model test conducted to investigate the punch-through of a flat footing with $30 \mathrm{~mm}$ diameter [7]. In addition, GeoPIV-RG programme was used to analyse the local strains developed in nonwoven geotextile during the wide width tensile testing [8]. However, no significant research study has been conducted to verify the applicability of this image based technique for measuring localised strain in any type of geogrid, comparing the strain gauge measurements. This research was conducted to verify the performance of strain gauges and to investigate the potential of using PIV technique and GeoPIV-RG software to measure the local strains developed in a composite geogrid specimen under tensile testing in the laboratory.

\section{PIV technique}

Digital Image Correlation (DIC) method is a widely accepted and commonly used surface deformation measurement technique, and this method is considered as a powerful and flexible tool to measure strains [9]. It is well known that PIV is a special class of DIC method. In principle, this technique will accurately predict strains, clearly identifying the provided 'particles' (of specific colour and texture) by the algorithm, which depends on the quality of the digital image captured during the experiment [10]. The same authors explained that appropriate shutter speed, light level and focus must be maintained, and the camera should be kept remain stationary on a firm tripod with no manual interference. Therefore, a computer is used for triggering the shutter opening.

The basic principle of DIC/PIV technique is to track the same points (or pixels) between un-deformed (or reference) and deformed states as schematically illustrated in Figure 1. The DIC/PIV method is considered as an optical metrology which involves both digital image processing and numerical computation. The surface strain field in the vertical direction (the direction of applied tensile force) can be determined from Equation (1) [10].

Generally, in PIV analysis, a region of interest (RoI) should be first defined on the initial/reference image. Then a mesh with patches (or subsets) of user defined size is created. Freely available PIV-DIC software such as MatPIV [11], GeoPIV [12], OpenPIV [13] and PIVlab [14] can be used to analyse images. A form of crosscorrelation is used in these software to obtain integer pixel displacements, and subpixel of the correlation peak is interpolated. However, these algorithms are based on "zero-order deformation" which means the deformation of subsets is not generally allowed. Therefore, a correlation between subsets is lost in regions where large deformations are experienced caused by a mismatch between the deformation being observed and the subset shape. However, an update of the GeoPIV program called GeoPIV-RG eliminates this issue as it incorporates higher-order (first order) subset shape functions [7].

(a)

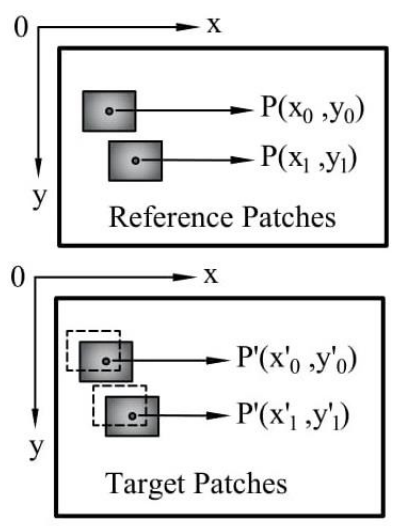

(b)

Fig. 1: Illustration of basic principle in PIV analysis [8]; (a) Reference Image; (b) Deformed Image

$$
\varepsilon_{\mathrm{yy}}=\partial \mathrm{u}_{\mathrm{y}} / \partial \mathrm{y}=\left\{\left(\mathrm{y}_{1}{ }^{\prime}-\mathrm{y}_{0}{ }^{\prime}\right)-\left(\mathrm{y}_{1}-\mathrm{y}_{0}\right)\right\} /\left(\mathrm{y}_{1}-\mathrm{y}_{0}\right)
$$

where $\varepsilon_{y y}$ is the surface strain field in the direction of applied tensile force.

\section{Materials and strain gauges}

\subsection{Geogrid}

As shown in Fig. 2, a composite geogrid made of Polypropylene was used in this research study. The properties of composite geogrid for both Machine Direction (MD) and Cross Machine Direction (CMD) provided by the manufacturer are shown in Table 1 . The nominal strength of the composite geogrid is $30 \mathrm{kN} / \mathrm{m}$ in both directions.

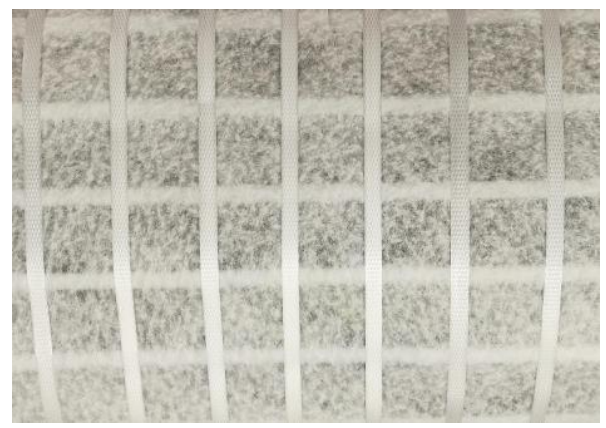

Fig. 2. Composite geogrid 
Table 1: Properties of composite geogrid

\begin{tabular}{|c|c|c|}
\hline Property & Units & $\mathrm{MD} / \mathrm{CMD}$ \\
\hline \multicolumn{3}{|l|}{ Geogrid } \\
\hline Maximum Tensile Strength & $\mathrm{kN} / \mathrm{m}$ & $\geq 30 / \geq 30$ \\
\hline Elongation at Nominal Strength & $\%$ & $\leq 8 / \leq 8$ \\
\hline Tensile Strength at $2 \%$ Elongation & $\mathrm{kN} / \mathrm{m}$ & $12 / 12$ \\
\hline Tensile Strength at $5 \%$ Elongation & $\mathrm{kN} / \mathrm{m}$ & $24 / 24$ \\
\hline Aperture Size & $\mathrm{mm}$ & $32 / 32$ \\
\hline \multicolumn{3}{|c|}{ Geotextile } \\
\hline Maximum Tensile Strength & $\mathrm{kN} / \mathrm{m}$ & $7.5 / 11$ \\
\hline $\begin{array}{l}\text { Elongation at Maximum Tensile } \\
\text { Strength }\end{array}$ & $\%$ & $40 / 30$ \\
\hline
\end{tabular}

\subsection{Strain gauges}

Two types of strain gauges were used in this experimental program. A three-wire quarter-bridge strain gauge (SG1) (Fig. 3 (a)) was used to verify its performance by comparing with strain calculated from PIV analysis. This type of strain gauge has a Gauge Factor (GF) of 2.11 at $20{ }^{\circ} \mathrm{C}$ and arm resistance of 120 $\Omega$, and it is suitable for measuring strains on materials such as plastic which has low elastic modulus compared to metal.

In wide-width tensile testing, strain gauges (SG2) (Fig. 3 (b)) were used in order to measure localised strains on composite geogrid test specimens. They have constantan metal foil grids with $120 \Omega$ arm resistance and the gauge factor of 2.14 at $20{ }^{\circ} \mathrm{C}$. This gauge has flexible polyimide backings and the copper coated solder tabs.

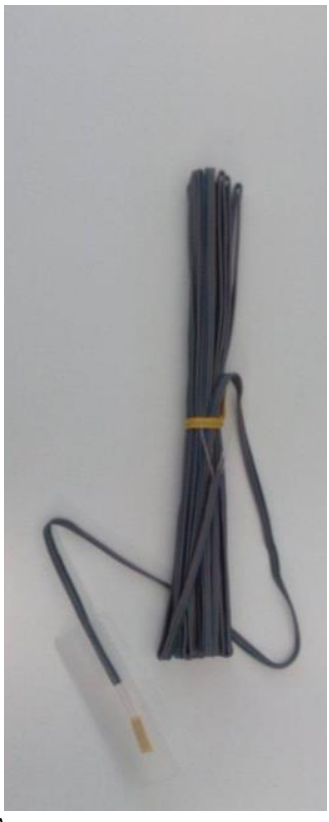

(a)

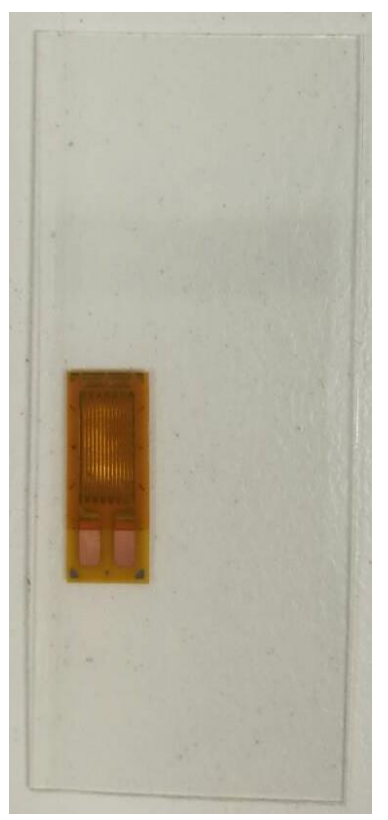

(b)
Fig. 3: Strain gauges used in this study; (a) SG1; (b) SG2

\section{Methodology}

The testing program consists of two phases. The performance verification of strain gauges was conducted in the first phase using a strain gauge attached to a composite-geogrid strip with a single rib. In the second phase, wide-width tensile tests were carried out according to BS EN ISO 10319:2015 on the composite geogrid test specimens attached with strain gauges. The constant strain rate of $10 \%$ per minute was applied to all geogrid tensile tests.

\subsection{Verification of strain gauge performance using a single rib geogrid strip}

Firstly, a $130 \mathrm{~mm}$ long and $57 \mathrm{~mm}$ wide composite geogrid specimen having a $7.5 \mathrm{~mm}$ wide single rib was prepared, and a standard strain gauge (SG1) was glued on the middle of the specimen in the direction of applied tensile force. Then the coating of the strain gauge was carried out in such a way that the first coating is with SB tape and the final coating is with VB tape (See Fig. 4). The purpose of the application of these coatings is to replicate the installation procedure of strain gauges on geogrids which will be used as soil reinforcements in civil engineering applications such as pavements and reinforced backfills. These coatings are used to protect the strain gauges from moisture and gravel particles. A resistor equal to the arm resistance of the strain gauge $(120 \Omega)$ was used as a bridge completion resistor with the strain gauge in order to balance the bridge.

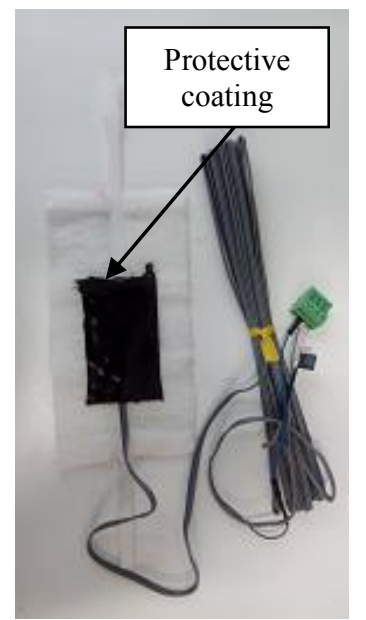

Fig. 4: A strain gauge (SG1) attached to a single rib geogrid strip

To perform PIV analysis, dots with a diameter of $2 \mathrm{~mm}$ were marked on the rib of the composite geogrid as shown in Fig. 5. Dots were marked using a permanent marker in such a way that the gap between two consecutive dots was less (approximately $5 \mathrm{~mm}$ ) near the strain gauge and larger (approximately $10 \mathrm{~mm}$ ) for other locations. Then, the geogrid specimen was set up in the Instron Universal Testing System (the capacity is $50 \mathrm{kN}$ ) as shown in Fig. 5. The specimen was subjected to monatomic tensile force by applying a constant strain rate of $10 \%$ per minute. During the test, photographs were taken every five seconds using a Digital Single 
Lens Reflex (DSLR) camera properly placed in front of the experimental setup as shown in Fig. 6.

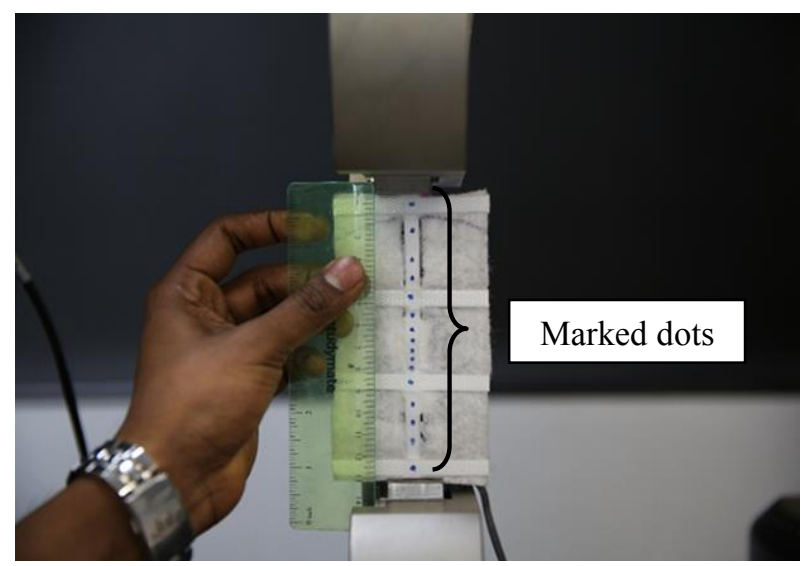

Fig. 5: The composite geogrid specimen set up in the Instron Universal Testing System

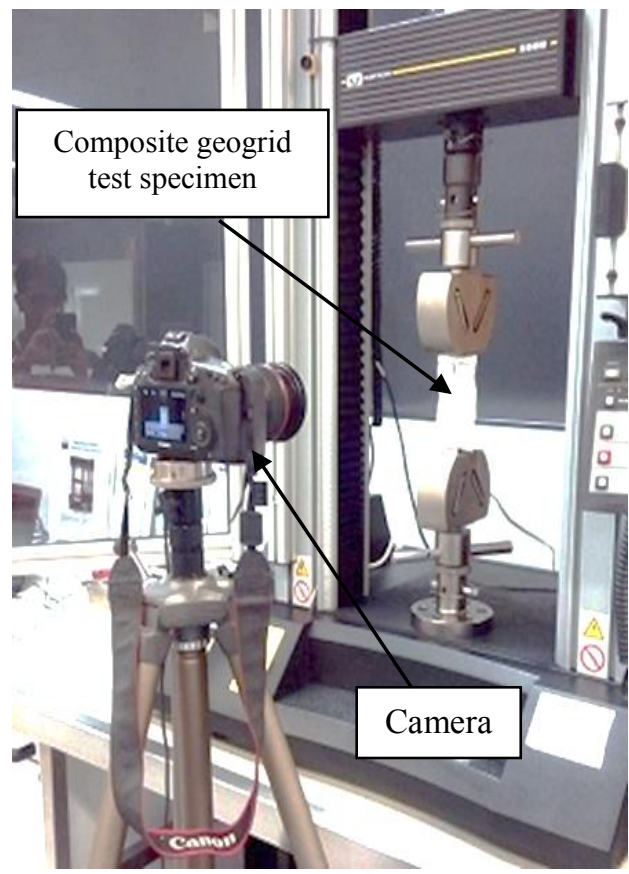

Fig. 6: The set up to take photographs for PIV analysis

During the test, the strain gauge responses were recorded for every second using a data logger. The data logger was set to calculate strains using the gauge factor and the response of the strain gauge. The global strain on the geogrid specimen was calculated considering the recorded extension values (crosshead movement) by the Instron Universal Testing System, and the initial length of the test specimen. The photographs taken during the test were analysed using Geo-PIV-RG software to calculate the local strains (using Equation 1) in the region where the strain gauge was attached. At the end of the test, the strains measured by the strain gauge, calculated from Geo-PIV-RG analysis and calculated from the crossheads movement of Instron apparatus were compared.

\subsection{Wide-width tensile testing}

Six test specimens were prepared in such a way that the width is $200 \mathrm{~mm}$ and length between the jaws is $100 \mathrm{~mm}$. A SG2 was glued on each specimen in the direction of applied tensile force. Dots were marked at the centre and junctions of each rib of test specimens using a permanent marker as shown in Fig. 7. The test geogrid specimen was clamped in the Instron Universal Testing System as in Fig. 7 and a tensile test was conducted according to BS EN ISO 10319. All the tensile tests were conducted with a constant strain rate of $10 \%$ per minute until the failure (break) of geogrids. During each test, the strains were measured/calculated using all three methods described in section 4.1. In all tests, strain gauges failed or detached before reaching $1 \%$ of strain.

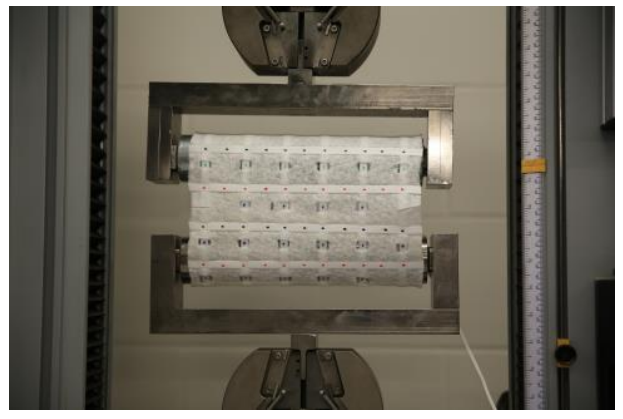

Fig. 7: A test specimen set up for wide-width tensile test

\section{Results and discussion}

Fig. 8 shows the load versus strain curves obtained from the tensile test on the single rib geogrid strip. Depending on the technique (e.g. strain gauge, PIV analysis, machine displacement) used to measure/calculate strain during the test, three curves are produced as shown in Fig.8. All three curves are produced up to the strain of $0.009(0.9 \%)$ as the strain gauge failed to respond after $0.9 \%$ of strain. The local strain measured by the strain gauge agrees well with that of calculated from the geoPIV-RG analysis at the same location of the strain gauge. From the results shown in Fig. 8, it can be suggested that both the geoPIV-RG analysis and properly installed strain gauges are able to measure local strains accurately. However, the accuracy of the strains measured by the strain gauges depends on a number of factors that have been discussed in section 1 (introduction). 


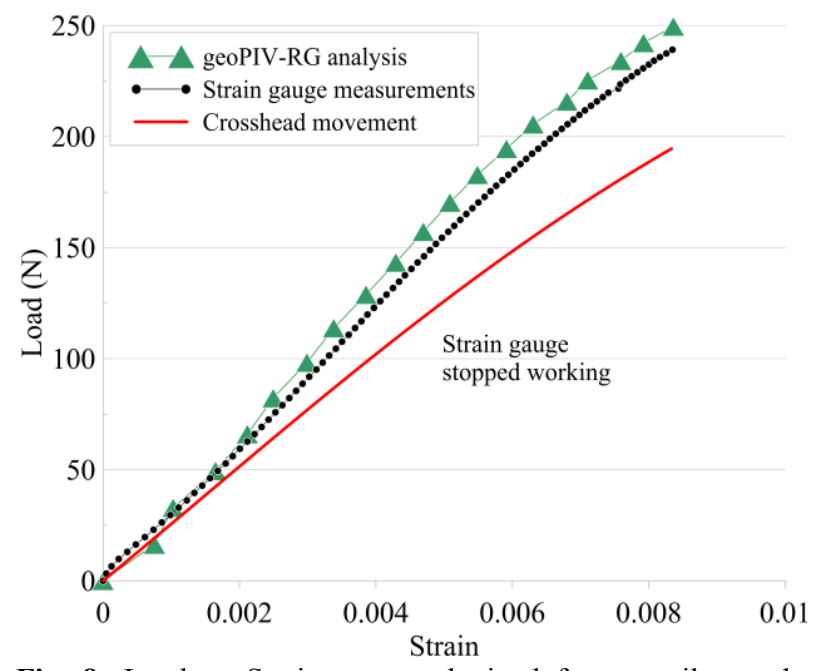

Fig. 8: Load vs Strain curves obtained from tensile on the single rib geogrid strip

Figure 9(a) and 9(b) depict load (per 1m width) vs strain curves obtained from two wide-width tensile tests on composite geogrid specimens. These results further confirm that both strain gauges and the geoPIV-RG analysis can be used to measure local strain on geogrids accurately. The results shown in Fig. 8 and 9 suggest that the geoPIV-RG analysis can be used to verify the performance of strain gauges attached on geogrids. So this type of verification test can be used to choose suitable strain gauges, to identify strain gauge installation procedure, and to choose and set up data logging for measuring strains on geogrids installed in the field applications. The geoPIV-RG analysis can successfully be used to measure strain in the laboratory tensile tests on geogrids when one has to measure strain more than $3 \%$ with a limited budget and less time consumption.

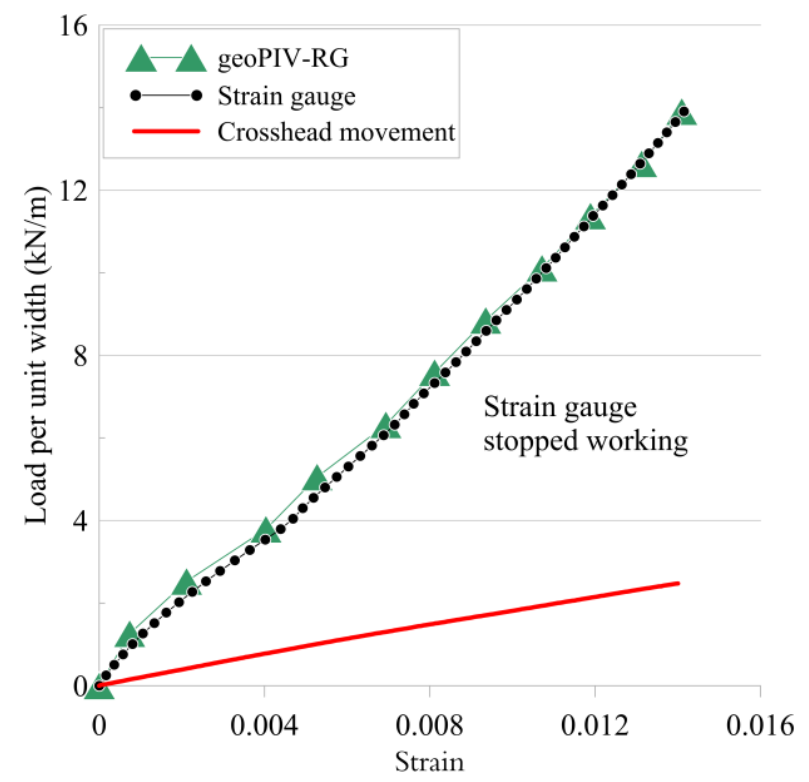

(a)

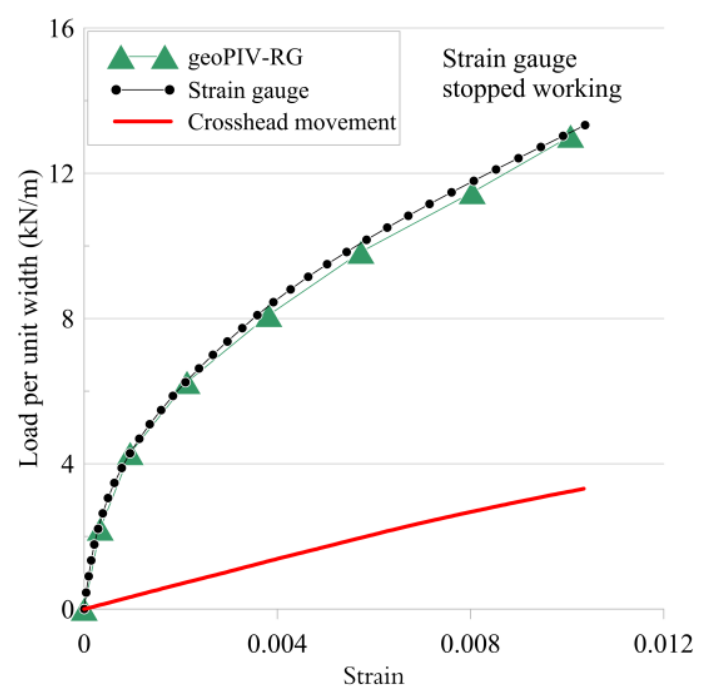

(b)

Fig. 9: Load per unit width - strain curves for two wide-width tensile test specimens; (a) Test 1; (b) Test 2

As shown in Fig. 8 and 9, the strain calculated from the crosshead displacement of the loading machine underestimate the tensile stiffness of geogrid. This technique calculates the overall strain of the specimen, and it is generally much higher than the values measured/calculated locally by strain gauges or geoPIV$\mathrm{RG}$ analysis at a given load. The reason for this miss match is the crosshead displacement measured by the loading machine can include machine deformation, slippage of the specimen at gripping points and the boundary effects at the grips.

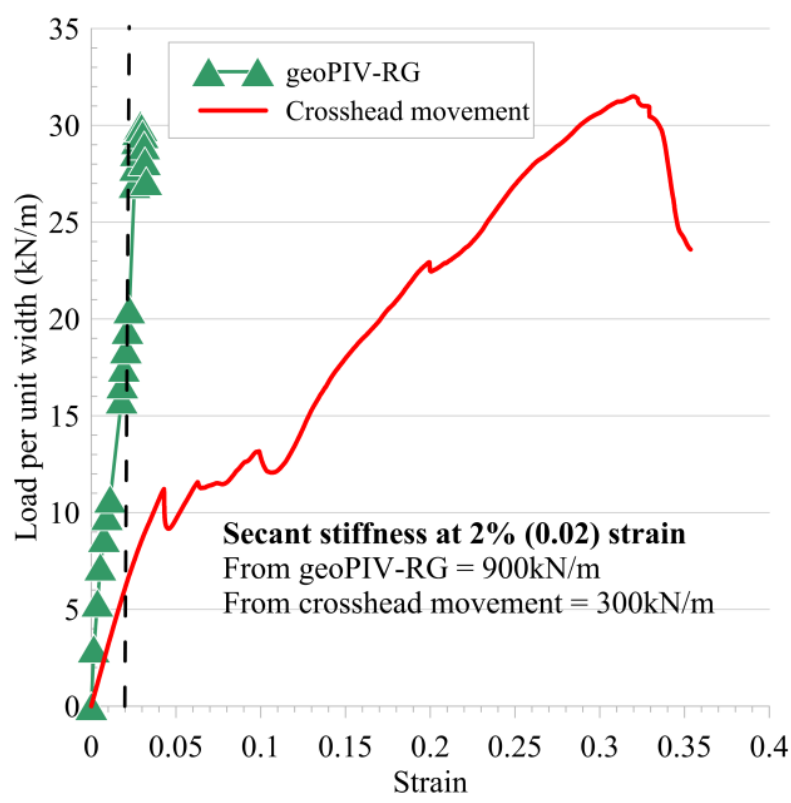

Fig. 10: Load per unit width/strain curve up to the failure of the geogrid specimen

Figure 10 shows load (per $1 \mathrm{~m}$ width) vs strain curves obtained from a wide-width tensile test on a composite geogrid specimen used. Strains were calculated using 
crosshead deformation of the tensile testing machine and using geoPIV-RG technique until the failure (rupture) of the test specimen. The maximum tensile strength (rupture strength) is measured as about $30 \mathrm{kN} / \mathrm{m}$, and this agreed with the value given in the material specification (Table 1). According to Fig. 10, the tensile strength at $2 \%$ is approximately $18 \mathrm{kN} / \mathrm{m}$ and $6 \mathrm{kN} / \mathrm{m}$ from geoPIV-RG analysis and crosshead movement of the apparatus, respectively. The material specification (Table 1 ) provides the tensile strength at $2 \%$ strain as 12 $\mathrm{kN} / \mathrm{m}$. Further, using the load-strain curves given in Fig. 10 , the scant stiffness of geogrid at $2 \%$ is calculated as $900 \mathrm{kN} / \mathrm{m}$, and $300 \mathrm{kN} / \mathrm{m}$ from load-strain curves obtained using geoPIV-RG analysis and crosshead deformation of the machine, respectively. It is clear from these results that the strains calculated from the movement of the crossheads of the tensile testing machine significantly under-estimate the tensile properties of the geogrid. Therefore, geoPIV-RG is suggested as a strain measuring technique in laboratory tensile tests on geogrids to determine their tensile properties accurately.

\section{Conclusion}

The study presented in this paper demonstrated how geoPIV-RG analysis can be used to verify the performance of strain gauges attached to geogrids and to emphasis the advantages of using geoPIV-RG technique in laboratory tensile tests on geogrids. The following conclusions can be drawn from this study:

- Both geoPIV-RG technique and properly installed strain gauges are able to measure local strains on geogrid accurately.

- GeoPIV-RG analysis can be used to verify the performance of strain gauges attached to geogrid and hence suitable strain gauges, installation procedure, and logging system can be suggested for monitoring of the field performance of a given geogrid type. This is due to the fact that applying PIV technique to measure local strains of geogrid specimens is not possible in the field applications.

- GeoPIV-RG is a low cost strain measuring technique to use in laboratory tensile testing on geogrids to determine their tensile properties accurately.

The authors acknowledge the continued support of the Department of Transport and Main Roads (TMR) and Australian Road Research Board (ARRB) by providing the required funding for the instruments including data logger and strain gauges for this research study and supplying the composite geogrid material. Thanks are also extended to the technical staff of Queensland University of Technology (QUT) for their great support and assistance during these tests. Further, the second author would like to thank QUT for providing him a scholarship to pursue his postgraduate studies. Authors are thankful to Prof Les Dawes for proof reading the paper for English.

\section{References}

1. J.G. Zornberg, Procedia Engineering., 189, 298-306 (2017)

2. K. Warren, B. Christopher, I. Howard, Geosynth. Int., 17(6), 403-430 (2010)

3. BS EN ISO 10319, Geosynthetics - Wide-width tensile test (2015)

4. A.H. Aydilek, M. Guler, T.B. Edil, J. Comput. Civil Eng. 18(1), 65-74 (2004)

5. M. E. Kutay, M. Guler, A.H. Aydilek, J. Geotech. Geoenviron., 132(1), 1-11 (2006)

6. M. Shinoda, R.J. Bathurst, Geotech. Test. J., 27(5), 456-463 (2005)

7. S.A. Stanier, J. Blaber, W.A. Take, D.J. White, Can. Geotech. J., 53(5), 727-739 (2015)

8. S. Mishra, S. Nithin, S. Mohapatra, K. Rajagopal, 6th Asian Regional Conference on Geosynthetics (2016)

9. B. Pan, K. Qian, H. Xie, A. Asundi, Meas. Sci. Technol., 20(6) 062001 (2009)

10. J. A. Thamboo, M. Dhanasekar, C. Yan, Aus. J. Struct. Eng., 14(3), 291-302 (2013)

11. J.K. Sveen, E.A. Cowen, PIV and water waves, 9, 149 (2004)

12. D. White, W. Take, M. Bolton, Geotechnique, 53(7), 619-631 (2003)

13. Z.J. Taylor, R. Gurka, G.A. Kopp, A. Liberzon, IEEE T. Instrum. Meas., 59(12), 3262-3269 (2010)

14. W. Thielicke, E.J. Stamhuis, J. Open Research Softw., 2(1) e.30, (2014) 